\title{
Características clínicas e intervenções fisioterapêuticas na tetraparesia espástica
}

\author{
Clinical characteristics and physiotherapeutic interventions \\ in spastic tetraparesis
}

\section{Características clínicas e intervenciones fisioterapéuticas en tetraparesis espástica}

\author{
Danielly Firmino da Silva ${ }^{1}$, Mayara Cristina Galindo de Moraes², \\ Marina Ortega Golin ${ }^{3}$
}

1.Graduada no curso de Fisioterapia do Centro Universitário Saúde ABC, Santo André-SP, Brasil. ORCID https://orcid.org/0000-0001-9308-436X

2.Graduada no curso de Fisioterapia do Centro Universitário Saúde ABC, Santo André-SP, Brasil. ORCID https://orcid.org/0000-0003-0355-0254

3.Docente da disciplina de Fisioterapia Neuropediátrica do Centro Universitário Saúde ABC, Santo AndréSP, Brasil.

\begin{abstract}
Resumo
Introdução. A Paralisia Cerebral (PC), acomete o sistema nervoso central em desenvolvimento maturacional e funcional. $\mathrm{Na}$ tetraparesia os quatros membros são acometidos igualmente. A espasticidade é a sequela motora mais comum na PC, sendo caracterizada por aumento do tônus muscular. Objetivo. Realizar revisão não sistemática da literatura sobre as características clínicas de pacientes com PC tetraparesia espástica e as modalidades de tratamento fisioterapêutico adotadas para essa população. Método. A busca foi feita nas bases de dados eletrônicas Medline, Lilacs e PEDro, com artigos publicados entre 2009 e 2019, nos idiomas português, inglês e espanhol. Resultados. Foram selecionados 18 artigos que abordaram as características clínicas e os diversos tipos de intervenção fisioterapêutica, sobre crioterapia, uso de vestes elásticas, equoterapia, cinesioterapia, fisioterapia aquática e conceito Bobath. Conclusão. As diversas estratégias de tratamento mostraram melhoras na aquisição motora e funcionalidade, detectadas por diferentes instrumentos de avaliação. Porém, devido ao baixo índice de descrições de abordagens e publicações realizadas, não é possível delimitar qual seria o método mais indicado e efetivo para o tratamento desses pacientes.
\end{abstract}

Unitermos. Paralisia Cerebral; Tetraparesia Espástica; Características Clínicas; Tratamento Fisioterapêutico

\footnotetext{
Abstract

Introduction. Cerebral Palsy $(\mathrm{CP})$ affects the central nervous system in maturational and functional development. In tetraparesis the four limbs are affected equally. Spasticity is the most common motor sequela in $\mathrm{CP}$, being characterized by increased muscle tone. Objective. It is a non systemact review about clinical characteristics of patients with $C P$ spastic tetraparesis and the physical therapy treatment modalities adopted for this population. Method. The search was done in the electronic databases Medline, Lilacs, and PEDro, for articles published from 2009 to 2019, in the languages Portuguese, English, and Spanish. Results. We selected 18 articles about the clinical features and the various types of intervention. The articles were on cryotherapy, wearing elastic garments, equine therapy, kinesiotherapy, aquatic physiotherapy, and Bobath concept. Conclusion. Several treatment strategies have shown improvements in motor functionality detected by different assessment tools. However, due to few descriptions of approaches and publications made, it is not possible to define which would be the most indicated and effective method for of these patients.

Keywords. Cerebral Palsy; Spastic Tetraparesis; Characteristics Clinics; Physiotherapeutic Treatment
} 


\section{Resumen}

Introducción. La parálisis cerebral (PC) afecta el sistema nervioso central en el desarrollo madurativo y funcional. En la tetraparesia, las cuatro extremidades se ven igualmente afectadas. La espasticidad es la secuela motora más común en la PC y se caracteriza por un aumento del tono muscular. Objetivo. Realizar una revisión no sistemática de la literatura sobre las características clínicas de los pacientes con PC con tetraparesia espástica y las modalidades de tratamiento fisioterapéutico adoptadas para esta población. Método. La búsqueda se realizó en las bases de datos electrónicas Medline, Lilacs y PEDro, con artículos publicados entre 2009 y 2019, en portugués, inglés y español. Resultados. Se seleccionaron dieciocho artículos que abordaron las características clínicas y los distintos tipos de intervención de fisioterapia, sobre crioterapia, uso de ropa elástica, hipoterapia, kinesioterapia, fisioterapia acuática y el concepto Bobath. Conclusión. Las diferentes estrategias de tratamiento mostraron mejoras en la adquisición y funcionalidad motora, detectadas por diferentes instrumentos de evaluación. Sin embargo, debido al bajo índice de descripciones de abordajes y publicaciones realizadas, no es posible delimitar cuál sería el método más indicado y efectivo para el tratamiento de estos pacientes.

Palabras clave. parálisis cerebral; tetraparesia espástica; características clínicas; tratamiento fisioterapéutico

Trabalho realizado no Centro Universitário Saúde ABC, Santo André-SP, Brasil.

\section{INTRODUÇÃO}

A Paralisia Cerebral (PC), designada como encefalopatia crônica não evolutiva da infância (ECNE), acomete o sistema nervoso central (SNC) em desenvolvimento maturacional e funcional. Ocorre durante os períodos pré-, peri- ou pósnatais, ocasionando prejuízos posturais, tônicos e de movimento, que persistem até a idade adulta. Suas causas são diversas, podendo ser de origem congênita, genética, infecciosa, traumática e inflamatória ${ }^{1}$.

Infelizmente, na maioria das vezes, o diagnóstico é tardio, entre os 18 e 24 meses de vida, implicando em atraso no desenvolvimento motor, que será definido de acordo com a localização, o tempo e a extensão da lesão no SNC. O grau de comprometimento varia desde um discreto prejuízo na destreza até uma severa paresia do paciente, 
impossibilitando a aquisição das etapas motoras, como rolar, sentar, engatinhar e deambular. O comprometimento motor pode estar associado a outras anomalias, tais como deficiência cognitiva, disfagia, convulsões e distúrbios de visão, fala, audição e comunicação².

A PC é classificada de acordo com o quadro clínico, podendo ser do tipo extrapiramidal (distônico, atetoide ou coreico), atáxico, hipotônico, espástico ou misto. Outra classificação é dada segundo a gravidade, se leve, moderada ou grave, sendo esse fator dependente da extensão do acometimento corpóreo. Na tetraparesia os quatros membros são acometidos igualmente, na diparesia também ocorre o acometimento dos quatros membros, porém os membros inferiores são mais afetados, já na hemiparesia o acometimento é de um hemicorpo 3 .

A espasticidade é a sequela motora mais comum na PC, sendo caracterizada por aumento do tônus muscular, devido à lesão no neurônio motor superior, estabelecendo um desequilíbrio entre a ação muscular de agonistas e antagonistas. Como consequência, gera aumento da resistência à movimentação passiva e diminuição da movimentação ativa, fraqueza muscular, espasmos, reflexos exacerbados, encurtamentos, deformidades musculares e perda de destreza, ou seja, impossibilita funções motoras normais.

Este tipo clínico afeta os grupos musculares com intensidades diferentes. Os transtornos são divididos em primário, secundário e terciário. No primário, observa-se a 
diminuição do movimento articular e do músculo afetado, que ocorre entre o primeiro e o terceiro ano de vida. No transtorno secundário observa-se encurtamentos de músculos e tendões e devido ao crescimento ósseo, podem gerar deformidades articulares e contraturas irredutíveis, entre os três e os doze anos de idade. Como consequência, ocorre o transtorno terciário, devido às compensações de posturas e movimentos anormais ${ }^{1}$.

Visando uma melhora global do paciente e sua integração na vida social é imprescindível que o tratamento ocorra com uma equipe multiprofissional composta por neuropediatra, ortopedista, psicólogo, fonoaudiólogo, terapeuta ocupacional e fisioterapeuta ${ }^{4}$.

Além de estimular o desenvolvimento neuropsicomotor e prevenir complicações secundárias, a fisioterapia tem como objetivo diminuir o tônus muscular anormal e promover maior independência nas atividades de vida diária, que inclui: aumentar e/ou manter a amplitude de movimento, força muscular e flexibilidade, visando melhora funcional. O método utilizado dependerá do quadro clínico apresentado, que será identificado durante uma avaliação específica, sendo considerado não somente 0 comprometimento biomecânico, mas também as alterações secundárias.

Dentre os recursos fisioterapêuticos utilizados, há a crioterapia que visa a diminuição da espasticidade causada pela aplicação do gelo 5 . O uso de vestes elásticas associado ao treinamento intensivo, como nos métodos TheraSuit e 
PediaSuit, tem como finalidade o alinhamento corporal, a eliminação de reflexos patológicos, adequação da marcha e o desenvolvimento de habilidades motoras finas e grossas ${ }^{6,7}$.

Já a cinesioterapia convencional é uma abordagem de tratamento que utiliza da atividade física para favorecer a função muscular esquelética ${ }^{8}$. A equoterapia é um método fisioterapêutico em que se utiliza da equitação para aquisição de habilidades motoras ${ }^{9}$. A fisioterapia aquática utiliza-se da piscina terapêutica e das propriedades físicas da água, proporcionando benefícios que cursam com alívio da dor e dos espasmos musculares, melhora da circulação e da capacidade respiratória ${ }^{10}$.

Dentre todas as possibilidades de intervenção fisioterapêuticas, o Conceito Bobath é atualmente o mais difundido e exercido em nosso meio. Sua abordagem preconiza a inibição dos reflexos primitivos e dos padrões patológicos, com base na sequência do desenvolvimento normal ${ }^{11}$.

Dessa forma, como a tetraparesia espástica é um dos tipos de PC mais frequentes, é de especial importância a realização de revisões atualizadas sobre o tema para que os profissionais da área de saúde e acadêmicos possam ser orientados. Principalmente no tocante à identificação e modificações do quadro clínico, às possibilidades de intervenção fisioterapêutica e suas respectivas efetividades.

Enfim, o objetivo dessa pesquisa foi realizar revisão não sistemática da literatura sobre as características clínicas de 
pacientes com PC tetraparesia espástica e as modalidades de tratamento fisioterapêutico adotadas para essa população.

\section{MÉTODO}

Foi realizada busca não sistemática na literatura, no período de dezembro de 2018 a junho de 2019, nas bases de dados eletrônicas Medline (National Library of Medicine), Lilacs (Literatura Latino-americana e do Caribe em Ciências da Saúde), e PEDro (Physiotherapy Evidence Database). Esta busca visou estudos publicados sobre as possibilidades de tratamento fisioterapêutico para crianças diagnosticadas com PC tetraparesia espástica e sua caracterização clínica.

A busca foi concentrada em artigos publicados entre os anos de 2009 a 2019, primeiramente em língua portuguesa e em seguida, nos idiomas inglês e espanhol.

As palavras-chave utilizadas, em português, foram: paralisia cerebral, quadriparesia espastica, fisioterapia; em inglês: quadriplegic infantile, cerebral palsy, physical therapy specialty, spastic; em espanhol: parálisis cerebral, cuadriplejía espasticidad, fisioterapia. Como estratégia de busca foi utilizada o $A N D$ entre os descritores supracitados.

Os critérios de inclusão para a seleção dos artigos foram abordagem de tratamentos fisioterapêutico, características clínicas, pacientes com paralisia cerebral do tipo tetraparesia espástica, artigos publicados em português, inglês e espanhol. Os artigos foram analisados, primeiramente, via leitura do título e resumo para obtenção de estudos pertinentes e relevantes para a pesquisa e posterior leitura 
na íntegra, selecionando apenas os artigos que tinham pertinência com o tema.

Os critérios de exclusão estabelecidos foram: artigos que abordassem intervenção cirúrgica, tratamento fisioterapêutico associado a tratamento farmacológico, outros tipos de topografias e artigos de revisão.

\section{RESULTADOS}

Foram selecionados 18 artigos $^{5,7-10,12-24}$ que abordaram a intervenção fisioterapêutica adotando crioterapia, vestes elásticas, cinesioterapia, fisioterapia aquática, equoterapia, conceito Bobath e as características clínicas de indivíduos com PC tetraparesia espástica. A Tabela 1 traz a síntese das informações dos três estudos encontrados sobre as características clínicas.

Em relação aos métodos de intervenção publicados, a maior quantidade de artigos encontrados foi sobre o Conceito Bobath, conforme demonstrado na Tabela 2. A Tabela 3 descreve os 10 artigos que adotaram os demais recursos fisioterapêuticos, tais como a crioterapia, vestes elásticas, cinesioterapia convencional, equoterapia e fisioterapia aquática.

\section{DISCUSSÃO}

Conforme os estudos apresentados nas tabelas, é possível verificar que as intervenções fisioterapêuticas aplicadas nos pacientes com paralisia cerebral tetraparesia espástica, auxiliaram de forma significativa quanto à 
adequação de tônus, melhora da espasticidade e, por consequência, melhora na qualidade de vida.

Tabela 1. Estudos sobre aspectos clínicos de crianças com PC tetraparesia espástica.

\begin{tabular}{|c|c|c|c|}
\hline $\begin{array}{c}\text { Autor, } \\
\text { ano }\end{array}$ & Objetivos & Método & Resultados \\
\hline $\begin{array}{l}\text { Morell } \\
2014^{12}\end{array}$ & $\begin{array}{l}\text { Avaliar a relação entre } \\
\text { alterações musculares } \\
\text { de tronco e de } \\
\text { endireitamento com o } \\
\text { desenvolvimento de } \\
\text { deformidades no } \\
\text { quadril }\end{array}$ & $\begin{array}{l}\text { Participaram } 10 \text { voluntários, } \\
\text { com média de } 9,6 \text { anos de } \\
\text { idade. Por meio de } \\
\text { eletromiografia, foi avaliada a } \\
\text { atividade dos músculos } \\
\text { eretores da coluna mediante à } \\
\text { desequilíbrios }\end{array}$ & $\begin{array}{l}\text { O alinhamento da coluna } \\
\text { vertebral pode afetar a } \\
\text { região pélvica, levando a } \\
\text { luxações/subluxações de } \\
\text { quadril }\end{array}$ \\
\hline $\begin{array}{l}\text { Catena } \\
2011^{13}\end{array}$ & $\begin{array}{l}\text { Avaliar o quadril de } \\
\text { pacientes, } \\
\text { considerando a } \\
\text { gravidade das } \\
\text { deformidades } \\
\text { articulares, a idade e } \\
\text { a escoliose }\end{array}$ & $\begin{array}{l}\text { Foram selecionados } 40 \\
\text { voluntários, idades de } 1 \text { a } 17 \\
\text { anos. Estabelecidos dois } \\
\text { grupos conforme a necessidade } \\
\text { ou não de tratamento cirúrgico } \\
\text { e avaliados por meio de testes } \\
\text { específicos para o quadril e de } \\
\text { gibosidade para escoliose }\end{array}$ & $\begin{array}{l}\text { Encontrada correlação entre } \\
\text { a escoliose e a positividade } \\
\text { do teste da abdução brusca } \\
\text { do quadril. Para a } \\
\text { correlação entre idade e } \\
\text { contratura articular não } \\
\text { houve significância }\end{array}$ \\
\hline $\begin{array}{l}\text { Tremblay } \\
2009^{14}\end{array}$ & $\begin{array}{l}\text { Identificar fatores que } \\
\text { predizem a } \\
\text { deambulação na PC } \\
\text { tetraparesia espástica }\end{array}$ & $\begin{array}{l}\text { Casuística com } 85 \text { crianças, } \\
\text { idades de } 1 \text { a } 4 \text { anos. Foram } \\
\text { analisados fatores pré-natais e } \\
\text { perinatais de pacientes } \\
\text { deambuladores e não } \\
\text { deambuladores }\end{array}$ & $\begin{array}{l}\text { Utilização de antibióticos } \\
\text { durante a gestação e crises } \\
\text { convulsivas nas primeiras } \\
72 \mathrm{~h} \text { foram associadas a não } \\
\text { deambulação }\end{array}$ \\
\hline
\end{tabular}

Nos pacientes com PC observam-se alterações musculoesqueléticas, que dificultam atividades do cotidiano esperadas para a idade, isso ocorre principalmente em virtude da espasticidade, secundariamente pelas alterações biomecânicas e fraqueza muscular. Uma das articulações mais frequentemente acometidas é o quadril, causando diminuição de ADM, contraturas, subluxações/luxações, o que prejudica o posicionamento do paciente, risco de aparecimento de úlceras por pressão e problemas quanto à higiene pessoal. 
Tabela 2. Estudos sobre intervenção fisioterapêutica, segundo Conceito Bobath.

\begin{tabular}{|c|c|c|c|}
\hline $\begin{array}{c}\text { Autor, } \\
\text { ano }\end{array}$ & Objetivos & Método & Resultados \\
\hline $\begin{array}{l}\text { Firmino } \\
2015^{15}\end{array}$ & $\begin{array}{l}\text { Avaliar a influência } \\
\text { do Conceito Bobath } \\
\text { na função muscular }\end{array}$ & $\begin{array}{l}\text { Estudo de caso, } 1 \\
\text { voluntário, idade } 7 \text { anos. } \\
\text { Avaliação clínica, física e } \\
\text { análise cinético-funcional } \\
\text { pela eletromiografia, } \\
\text { durante o repouso e a } \\
\text { intervenção com os } \\
\text { manuseios do Bobath }\end{array}$ & $\begin{array}{l}\text { Observou-se maior } \\
\text { ativação dos músculos } \\
\text { oblíquo transverso do } \\
\text { abdome e dos } \\
\text { paravertebrais durante os } \\
\text { manuseios }\end{array}$ \\
\hline $\begin{array}{l}\text { Castaño } \\
2019^{16}\end{array}$ & $\begin{array}{l}\text { Identificar os } \\
\text { efeitos do Bobath } \\
\text { sobre a função } \\
\text { motora }\end{array}$ & $\begin{array}{l}\text { Estudo de caso, } 1 \\
\text { voluntário, idade } 9 \text { anos, } \\
\text { nível funcional V, segundo } \\
\text { Sistema de Classificação da } \\
\text { Função Motora Grossa } \\
\text { (GMFCS). } \\
\text { Aplicado o conceito Bobath } \\
\text { durante } 16 \text { semanas, } \\
\text { totalizando } 80 \text { sessões e } \\
\text { avaliado através da escala } \\
\text { Gross Motor Funciton } \\
\text { Measure (GMFM-66) e } \\
\text { Escala Modificada de } \\
\text { Ashworth (EMA) }\end{array}$ & $\begin{array}{l}\text { Os resultados apontam } \\
\text { para alterações positivas } \\
\text { nos escores brutos da } \\
\text { função motora, de } 0,0 \\
\text { para } 14,8 \text { e } 20,5 \\
\text { observadas na } 12^{a} \text { e } 16^{a} \\
\text { semanas respectivamente }\end{array}$ \\
\hline $\begin{array}{l}\text { Ávila } \\
2014^{17}\end{array}$ & $\begin{array}{l}\text { Analisar a atuação } \\
\text { da fisioterapia com } \\
\text { o Bobath em } \\
\text { paciente com PC }\end{array}$ & $\begin{array}{l}\text { Estudo de caso, } 1 \\
\text { voluntário, idade } 4 \text { anos. } \\
\text { Realizados } 11 \text { atendimentos } \\
\text { com o conceito Bobath e } \\
\text { avaliado através do } \\
\text { desenvolvimento } \\
\text { neuropsicomotor }\end{array}$ & $\begin{array}{l}\text { Redução da espasticidade } \\
\text { observado pela EMA, com } \\
\text { melhora neuromotora e de } \\
\text { funcionalidade, segundo a } \\
\text { GMFCS }\end{array}$ \\
\hline $\begin{array}{l}\text { Gomes } \\
2012^{18}\end{array}$ & $\begin{array}{l}\text { Descrever o } \\
\text { tratamento } \\
\text { fisioterapêutico em } \\
\text { crianças com PC } \\
\text { tetraparesia } \\
\text { espástica }\end{array}$ & $\begin{array}{l}\text { Participaram três crianças, } \\
\text { com média de } 3,7 \text { anos de } \\
\text { idade. Foram selecionadas } \\
\text { as condutas aplicadas com } \\
\text { maior frequência }\end{array}$ & $\begin{array}{l}\text { As condutas visavam } \\
\text { principalmente diminuir o } \\
\text { tônus; aumentar } \\
\text { extensibilidade, controle } \\
\text { cervical e de cintura } \\
\text { escapular }\end{array}$ \\
\hline $\begin{array}{l}\text { Porras } \\
2019^{19}\end{array}$ & $\begin{array}{l}\text { Comparar os efeitos } \\
\text { do conceito Bobath } \\
\text { sobre a atenção } \\
\text { visual em crianças } \\
\text { com PC }\end{array}$ & $\begin{array}{l}\text { Foram incluídos } 10 \\
\text { voluntários, com idades de } \\
\quad 6 \text { a } 16 \text { anos. Elaborados } \\
\text { grupos controle e } \\
\text { experimental. As avaliações } \\
\text { ocorrem pré e pós } \\
\text { tratamento pelo teste de } \\
\text { atenção de Conner para } \\
\text { crianças (KCPT) }\end{array}$ & $\begin{array}{l}\text { O conceito Bobath } \\
\text { mostrou-se instrumento } \\
\text { válido para melhorar o } \\
\text { controle motor visual }\end{array}$ \\
\hline
\end{tabular}


Tabela 3. Estudos que abordaram demais métodos de intervenção fisioterapêutica.

\begin{tabular}{|c|c|c|c|}
\hline $\begin{array}{c}\text { Autor, } \\
\text { ano }\end{array}$ & Objetivos & Método & Resultados \\
\hline $\begin{array}{l}\text { Santos } \\
2019^{5}\end{array}$ & $\begin{array}{l}\text { Avaliar o efeito } \\
\text { agudo da } \\
\text { crioterapia na } \\
\text { modulação da } \\
\text { espasticidade e } \\
\text { amplitude de } \\
\text { movimento (ADM) }\end{array}$ & $\begin{array}{l}\text { Participaram quatro } \\
\text { voluntários, com média de } 9 \\
\text { anos de idade. Foi realizada } \\
\text { aplicação de crioterapia no } \\
\text { músculo bíceps braquial } \\
\text { espástico, por } 20 \text { minutos. } \\
\text { Foi avaliado o grau de } \\
\text { espasticidade pela EMA e a } \\
\text { ADM pelo sistema de } \\
\text { eletrogoniometria }\end{array}$ & $\begin{array}{l}\text { Redução da espasticidade } \\
\text { em três voluntários } \\
\text { mostrada } \\
\text { pela EMA e aumento } \\
\text { da ADM em todos }\end{array}$ \\
\hline $\begin{array}{l}\text { Ferreira } \\
2011^{20}\end{array}$ & $\begin{array}{l}\text { Analisar o efeito da } \\
\text { crioterapia e do } \\
\text { ultrassom (UST) } \\
\text { na redução da } \\
\text { espasticidade }\end{array}$ & $\begin{array}{l}\text { Estudo de caso, } 22 \text { anos. } \\
\text { Tratamento composto por } \\
14 \text { sessões, duração de } 30 \\
\text { minutos sobre músculo } \\
\text { bíceps braquial. Avaliada } \\
\text { ADM de maneira subjetiva e } \\
\text { espasticidade pela EMA }\end{array}$ & $\begin{array}{l}\text { Melhora na ADM e nos } \\
\text { níveis } \\
\text { de espasticidade, pela } \\
\text { EMA }\end{array}$ \\
\hline $\begin{array}{l}\text { Oliveira } \\
2018^{7}\end{array}$ & $\begin{array}{l}\text { Investigar a } \\
\text { efetividade do } \\
\text { Pediasuit na } \\
\text { função motora } \\
\text { grossa }\end{array}$ & $\begin{array}{l}\text { Estudo de caso, idade } 6 \\
\text { anos. Terapia intensiva } \\
\text { realizada durante } 21 \\
\text { sessões. Avaliado através } \\
\text { da GMFM-66 }\end{array}$ & $\begin{array}{l}\text { Aumento das atividades } \\
\text { motoras representadas das } \\
\text { dimensões D (de pé) e E } \\
\text { (andar, correr e pular) da } \\
\text { escala GMFM-66 }\end{array}$ \\
\hline $\begin{array}{l}\text { Oliveira } \\
2018^{21}\end{array}$ & $\begin{array}{l}\text { Analisar as } \\
\text { oscilações de } \\
\text { tronco } \\
\text { antes e após } \\
\text { (Terapia } \\
\text { Neuromotora } \\
\text { Intensiva) TNMI } \\
\text { associada ao } \\
\text { PediaSuit }\end{array}$ & $\begin{array}{l}\text { Participaram cinco } \\
\text { voluntários, com média de } \\
\text { idade de 5,2 anos. Terapia } \\
\text { realizada durante } 20 \\
\text { sessões, associando a TNMI } \\
\text { com o método PediaSuit. } \\
\text { Avaliados pela GMFM, } \\
\text { especificamente na } \\
\text { dimensão B (sentar) }\end{array}$ & $\begin{array}{l}\text { Melhora no controle de } \\
\text { tronco e } \\
\text { consequentemente na } \\
\text { função motora grossa na } \\
\text { dimensão B (sentar) da } \\
\text { GMFM }\end{array}$ \\
\hline $\begin{array}{l}\text { Silva } \\
2014^{22}\end{array}$ & $\begin{array}{l}\text { Descrever a } \\
\text { abordagem } \\
\text { terapêutica, em } \\
\text { uma criança com } \\
\text { PC com } \\
\text { tetraparesia } \\
\text { espástica }\end{array}$ & $\begin{array}{l}\text { Estudo de caso, idade } 6 \\
\text { anos. Utilizadas as escalas } \\
\text { GMFM, GMFCS e a } \\
\text { Classificação Internacional } \\
\text { de Funcionalidade, } \\
\text { Incapacidade e Saúde (CIF) } \\
\text { para descrever as principais } \\
\text { características do paciente. } \\
\text { Tratamento realizado com } \\
\text { exercícios terapêuticos } \\
\text { baseados na fase do } \\
\text { desenvolvimento que a } \\
\text { criança se encontrava, } \\
\text { realizado duas vezes } \\
\text { semanais, durante seis anos }\end{array}$ & $\begin{array}{l}\text { Melhora nas escalas GMFM } \\
\text { e GMFCS, onde nesta } \\
\text { última foi observada a } \\
\text { evolução do nível V para o } \\
\text { nível IV, contribuindo para } \\
\text { o desenvolvimento motor }\end{array}$ \\
\hline
\end{tabular}


Tabela 3 (cont.). Estudos que abordaram demais métodos de intervenção fisioterapêutica.

\begin{tabular}{|c|c|c|c|}
\hline $\begin{array}{c}\text { Autor, } \\
\text { ano }\end{array}$ & Objetivos & Método & Resultados \\
\hline $\begin{array}{l}\text { Espindula } \\
2018^{8}\end{array}$ & $\begin{array}{l}\text { Avaliar os } \\
\text { benefícios da } \\
\text { fisioterapia } \\
\text { convencional para } \\
\text { flexibilidade em PC } \\
\text { espástica }\end{array}$ & 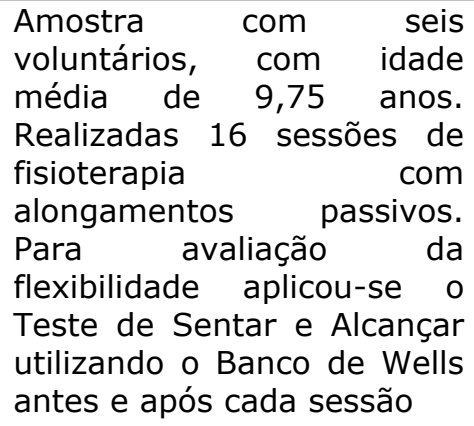 & $\begin{array}{l}\text { Aumento da flexibilidade } \\
\text { da cadeia muscular } \\
\text { posterior }\end{array}$ \\
\hline $\begin{array}{l}\text { Pastrello } \\
2009^{10}\end{array}$ & $\begin{array}{l}\text { Investigar a } \\
\text { eficácia do método } \\
\text { Watsu como } \\
\text { recurso } \\
\text { complementar no } \\
\text { tratamento } \\
\text { fisioterapêutico de } \\
\text { uma criança com } \\
\text { PC }\end{array}$ & $\begin{array}{l}\text { Estudo de caso, } 4 \text { anos de } \\
\text { idade. Tratamento realizado } \\
\text { em duas etapas, sendo a } \\
\text { primeira composta por } \\
16 \text { sessões em solo e a } \\
\text { segunda por } 24 \text { sessões, } \\
\text { associando terapia em solo } \\
\text { com o método Watsu. Para } \\
\text { avaliar a função motora, } \\
\text { utilizou-se as dimensões A } \\
\text { (deitar e rolar) e B (sentar) } \\
\text { da escala GMFM }\end{array}$ & $\begin{array}{l}\text { Melhora do desempenho } \\
\text { motor na dimensão A } \\
\text { (deitar e rolar) da GMFM } \\
\text { somente na segunda etapa }\end{array}$ \\
\hline $\begin{array}{l}\text { Navarro } \\
2009^{23}\end{array}$ & $\begin{array}{l}\text { Verificar a } \\
\text { importância da } \\
\text { hidrocinesioterapia } \\
\text { no tratamento da } \\
\text { paralisia cerebral } \\
\text { para a manutenção } \\
\text { e/ou melhora do } \\
\text { quadro clínico }\end{array}$ & $\begin{array}{l}\text { Estudo de caso, idade } 34 \\
\text { anos. Tratamento realizado } \\
\text { durante } 11 \text { meses, com } \\
\text { frequência de duas vezes } \\
\text { semanais, dividido em duas } \\
\text { etapas, sendo a primeira de } \\
\text { adaptação e ajuste ao meio } \\
\text { e a segunda com exercícios } \\
\text { independentes. Utilizadas } \\
\text { avaliações subjetivas }\end{array}$ & $\begin{array}{l}\text { Melhora no equilíbrio e } \\
\text { manutenção da } \\
\text { independência motora do } \\
\text { paciente }\end{array}$ \\
\hline $\begin{array}{l}\text { McGee } \\
2009^{24}\end{array}$ & $\begin{array}{l}\text { Examinar os } \\
\text { efeitos imediatos } \\
\text { da sessão de } \\
\text { equoterapia na } \\
\text { marcha }\end{array}$ & $\begin{array}{l}\text { Casuística com nove } \\
\text { voluntários, idades de } 7 \text { a } \\
18 \text { anos. Coleta de dados } \\
\text { dos parâmetros da marcha } \\
\text { após uma sessão de } \\
\text { equoterapia }\end{array}$ & $\begin{array}{l}\text { Não foram observadas } \\
\text { diferenças significantes nos } \\
\text { valores dos parâmetros } \\
\text { temporais e espaciais da } \\
\text { marcha }\end{array}$ \\
\hline $\begin{array}{l}\text { Gregório } \\
2013^{9}\end{array}$ & $\begin{array}{l}\text { Avaliar a influência } \\
\text { da equoterapia no } \\
\text { controle cervical e } \\
\text { de tronco }\end{array}$ & $\begin{array}{l}\text { Estudo de caso, idade } 2 \\
\text { anos. O tratamento foi } \\
\text { realizado em nove sessões, } \\
\text { associados com } \\
\text { alongamentos } \\
\text { globais anteriores à terapia. } \\
\text { Avaliação realizada pela } \\
\text { GMFM }\end{array}$ & $\begin{array}{l}\text { Adquiriu-se controle de } \\
\text { cervical e controle de } \\
\text { tronco após as sessões, } \\
\text { incrementando } \\
\text { percentualmente as } \\
\text { dimensões A (deitar e } \\
\text { rolar) e B (sentar) da } \\
\text { GMFM }\end{array}$ \\
\hline
\end{tabular}


Estudos afirmam que a presença de comorbidades pode estar diretamente correlacionada ao aparecimento de escoliose e capacidade de atingir marcha independente ${ }^{13,14}$.

O estudo realizado por Morell $2014^{12}$ avaliou a resposta da atividade muscular dos eretores da coluna frente ao desequilíbrio, questionando sua associação com as luxações e subluxações de quadril em pacientes com PC tetraespástica, via análise de 10 pacientes, com idade média de 9,6 anos, classificados como nível $\vee$ da escala GMFCS. As avaliações ocorreram por meio de desequilíbrios provocados em sentidos lateral e anteroposterior. Notou-se que diminuição da contração destes músculos afeta a estabilidade, alinhamento biomecânico e pode ser predisponente ao aparecimento de escoliose, além de estar associadas às luxações e subluxações de quadril.

Fato corroborado pelo estudo de Catena $2011^{13}$ ao observar que a escoliose está associada a um pior grau de contratura dos quadris. Os autores avaliaram 40 pacientes, com idades entre 01 e 17 anos, 95\% pertencia ao nível $\mathrm{V}$ e $5 \%$ ao nível IV da escala GMFCS. Por meio de testes específicos, foi observado que o desequilíbrio muscular e ausência da deambulação são quadros agravantes para danos no quadril e que a escoliose exacerba a contração muscular durante o movimento de abdução da articulação em questão. Um dado importante foi não haver correlação significante entre a idade dos pacientes e o grau de contratura do quadril. 
Tremblay $2009^{14}$ a fim de analisar quais são os fatores determinantes para que pacientes diagnosticados com PC tetraespástica possam realizar a marcha, investigaram 85 pacientes, por testes específicos. Embora sem valores estatisticamente significativos, encontrou que a ingestão de antibióticos durante a gestação e presença de convulsão no recém-nascido nas primeiras 72 horas são fatores que podem contribuir para incapacitar o desenvolvimento da deambulação. Em relação à aquisição da marcha independente, os dados apontam associação com idade gestacional ao nascimento acima de 27 semanas.

O Conceito Bobath é um dos recursos mais utilizados para tratamento de lesões do Sistema Nervoso Central (SNC), pois apresenta o objetivo principal de trabalhar as alterações sensório-motoras e funcionais. Tem como base a neuroplasticidade, que foca em pontos chaves por meio de manuseios que facilitem a adequação do tônus e reeducação do movimento ${ }^{15}$.

Partindo dos objetivos funcionais do método, Ávila $2014^{17}$ avaliaram e elaboraram um tratamento composto de 11 sessões, para uma criança de quatro anos de idade, que não permanecia sentada sem apoio. Foram observadas melhorias na realização de atividades funcionais, equilíbrio, espasticidade e ganho neuromotor. 0 método também foi aplicado por Castaño $2019^{16}$, que objetivava a identificação dos efeitos do conceito Bobath na função motora grossa de uma criança com nove anos de idade, que realizava tratamento há oito anos de maneira convencional. 0 
tratamento durou 80 sessões e foi verificada a diminuição da espasticidade em membros superiores e evolução na escala GMFM, na qual, nas dimensões A (deitar e rolar) e B (sentar) foram observadas as aquisições de estender o braço e cruzálos em linha média e também o apoio cefálico.

Com objetivo semelhante ao de Castaño 201916, Firmino $2015^{15}$ avaliaram a influência e a eficácia do método com uma criança de 7 anos de idade. A intervenção ocorreu em uma única sessão, com repetições estabelecidas a partir do desempenho do voluntário. Os dados foram coletados através de eletrodos que monitoravam a ação dos músculos paravertebrais e oblíquo interno do abdome. Houve maior ativação de fibras motoras desses músculos durante a mobilização pélvica, o que pode justificar um melhor alinhamento postural e habilidade para realização de atividades funcionais.

Ao descrever o tratamento fisioterapêutico utilizando o conceito Bobath, realizado em uma clínica escola, Gomes $2012^{18}$ verificaram as condutas adotadas com maior frequência em três crianças, com idades entre três e sete anos, que já realizavam tratamento fisioterapêutico. As autoras salientaram a importância de condutas apropriadas e individualizadas no objetivo de promover o potencial funcional máximo da criança para aquisição de etapas do desenvolvimento motor. A prescrição de órteses foi abordada como método de prevenir deformidades e auxiliar na funcionalidade. Ressaltam também, a importância de finalizar a terapia na posição ortostática, a fim de permitir 
propriocepção e integração do que foi estimulado, além de promover e favorecer a função dos órgãos.

Abordando outra vertente, pouco estudada, Porras $2019^{19}$ compararam os efeitos do conceito Bobath na atenção visual de crianças com PC tetraparesia espástica. Foram incluídas 10 crianças com idade média de 12 anos. As avaliações ocorreram através da Kiddie Continuous Performance Test (K-CPT), que fornece índice de estimativa ao diagnóstico de Transtorno de deficit de atenção com hiperatividade (TDAH). Após as intervenções, observou-se que a melhora do controle da cabeça influenciou na melhora da atenção visual, pois um tônus muscular mais adequado facilita os movimentos dos olhos e da cabeça contra a gravidade. Verificou-se também, que pacientes com PC possuem alta prevalência de TDAH, mas são mais frequentes em pacientes com acometimento topográfico aqui relacionado.

A termoterapia é uma modalidade da fisioterapia que utiliza do aumento ou diminuição da temperatura para readequar a ação muscular. Sendo que a crioterapia diminui a neurotransmissão de impulsos aferentes e eferentes, reduzindo os reflexos osteotendíneos e cutâneos, que são altamente sensíveis nos músculos espásticos. Enquanto o calor produz efeito analgésico devido a redução da viscosidade dos tecidos, permitindo maior tolerância ao alongamento 20 .

No estudo de caso realizado por Ferreira $2011^{20}$ foram aplicadas as técnicas de crioterapia e ultrassom 
contínuo, por 14 sessões, em uma paciente que não realizava tratamento fisioterapêutico. A aplicação do gelo foi realizada no ventre do músculo bíceps braquial durante 30 minutos, simultaneamente com a aplicação de US durante 10 minutos. Foram observados aumento da ADM da extensão passiva de cotovelo em 11 sessões e diminuição do grau de espasticidade em sete sessões.

Já no estudo de Santos 20195, realizado com quatro participantes, idades entre sete e 11 anos, que realizavam tratamento com TNMI, a aplicação do gelo ocorreu por 20 minutos, também, na região do ventre muscular do bíceps braquial. A escolha de um tempo de aplicação inferior foi estabelecida por um setup experimental, no qual verificouse que em 20 minutos era possível obter efeito na modulação da espasticidade, mantendo os voluntários seguros e sem risco de lesões. Foi realizada uma única aplicação e observou-se aumento da ADM em todos os participantes e diminuição da Escala Modificada de Asworth (EMA) em 75\% dos voluntários. Contudo, ambos estudos assentem que a utilização da termoterapia deve ser realizada de forma coadjuvante à outra terapia.

O uso de vestes elásticas consiste na aplicação de uma órtese suave, proprioceptiva e dinâmica que têm como objetivo aumentar força e a resistência muscular, favorecendo o alinhamento corporal e facilitando 0 desempenho dos movimentos da biomecânica funcional. Promove estímulos repetitivos e intensos no SNC, proporcionando plasticidade neuronal que colabora para 
melhora do controle motor, enfoca a propriocepção e busca recuperar o atraso neuropsicomotor ${ }^{7}$.

Oliveira $2018^{7}$ constataram a eficácia do método PediaSuit em estudo de caso realizado com uma criança seis anos, classificada no nível III do GMFCS que não realizava nenhuma outra intervenção terapêutica. $O$ tratamento foi realizado por 21 semanas, de segunda à sexta-feira, com duração de quatro horas diárias. Todos os atendimentos eram iniciados com alongamentos passivos e movimentação ativa das articulações. A vestimenta era de acordo com a necessidade de alinhamento biomecânico apresentado. Notou-se aumento da capacidade motora nas dimensões B, C, D e E da GMFM-66, especialmente nas D (de pé) e E (andar, correr e pular). A intensidade da terapia pode ter influenciado nos ganhos precoces após a intervenção, observando melhora da postura sentada, na realização de transferência sem auxílio das mãos e no equilíbrio estático e dinâmico, visto que a voluntária em questão adquiriu marcha independente a curtas distâncias.

Em outro estudo, Oliveira $2018^{21}$ associaram o uso de TNMI ao método PediaSuit, a fim de avaliar o efeito do tratamento no controle na oscilação de tronco. A intervenção foi realizada em cinco crianças, com idade média de 5,2 anos. Assim como no estudo anterior, o tratamento foi realizado por quatro horas diárias, cinco vezes por semana, durante quatro semanas. Dentre os pacientes, somente um manteve a pontuação alcançada na avaliação inicial, os 
demais apresentaram melhora na função motora grossa, identificada pela dimensão B (sentar) da GMFM.

A cinesioterapia é um recurso fisioterapêutico que visa a funcionalidade física por meio do planejamento de exercícios que resultam na melhora do alinhamento biomecânico, do condicionamento físico, da qualidade de vida e do desenvolvimento neuropsicomotor ${ }^{8}$.

Espindula $2018^{8}$ avaliaram quatro crianças, com idade média de 9,75 anos. Para verificarem os benefícios da fisioterapia convencional para flexibilidade a curto e longo prazo destes pacientes, desenvolveram um protocolo de tratamento com duração 16 sessões, realizadas semanalmente. 0 protocolo foi composto por seis exercícios que consistiam em alongamento da cadeia muscular de membros inferiores e dos músculos paravertebrais. Embora não tenha sido empregado um follow up a fim de acompanhar a resposta em longo prazo, o protocolo mostrou-se eficaz, com ganho de flexibilidade, que permaneceu ao longo do tratamento.

Já no estudo realizado por Silva $2014^{22}$ com um paciente de seis anos de idade, foram empregadas atividades lúdicas baseadas na fase do desenvolvimento em que a criança se encontrava e no grau de comprometimento sensório-cognitivo-motor. Os exercícios objetivaram a flexibilidade e a manutenção e exploração das posturas prona, supina, sentada, ajoelhada e em ortostatismo, realizados duas vezes por semana, desde um ano de idade. As avaliações adotadas foram a CIF, GMFM, dimensões $A$ 
(deitar e rolar) e B (sentado) e o GMFCS. Observou-se que a reabilitação, em longo prazo, viabiliza a socialização, adaptação familiar e principalmente, aquisição do desenvolvimento neuropsicomotor. Foi possível acompanhar a evolução do paciente na escala GMFCS, passando do nível V para o nível IV.

A piscina terapêutica tem como principais benefícios 0 alívio da dor e do espasmo muscular; aumento da ADM; fortalecimento muscular global; melhora da circulação, equilíbrio, coordenação motora e postura. O método Watsu é composto por alongamentos, movimentos rítmicos, rotacionais e manipulações articulares, em que 0 fisioterapeuta oferece apoio total na água ${ }^{10,23}$.

Navarro $2009^{23}$ selecionaram um paciente de 34 anos de idade, considerado independente nas AVD's e com deambulação dificultada. O tratamento com fisioterapia aquática foi realizado por 11 meses, composto por duas etapas, sendo a primeira a adaptação e ajuste do paciente ao meio, exercícios passivos e de relaxamento e na segunda etapa preconizou-se exercícios realizados de maneira ativa, marcha e fortalecimento muscular. Obteve-se melhora do equilíbrio e manutenção da independência motora.

Da mesma forma, Pastrello $2009^{10}$ realizaram o tratamento em piscina terapêutica em uma criança de quatro anos de idade, que não realizava outra intervenção fisioterapêutica. Também foi realizado em duas etapas, porém, divididas entre solo e solo associado ao meio aquático, por 40 semanas. Em que se pôde ampliar as 
vertentes de avaliações, comparando deste modo, o momento pré-intervenção, intervenção em solo e pósintervenção em solo associado ao meio aquático, que ocorreram pela escala GMFM, dimensões $A$ (deitar e rolar) e B (sentado). Ambas as etapas utilizaram o meio lúdico para maior adaptação da criança. A primeira foi baseada na estimulação das fases de desenvolvimento neuropsicomotor, via terapia convencional e a segunda pelo protocolo de Watsu. O estudo mostrou melhora na aquisição da função motora grossa apenas após a segunda etapa do tratamento proposto.

A equoterapia tem como principais benefícios 0 alinhamento biomecânico, melhora do equilíbrio e da coordenação motora, maior controle de tronco e aumento de força muscular, possibilitando assim, a diminuição da espasticidade. Além de permitir ao paciente contato com o cavalo, possibilita uma terapia lúdica, abrange também melhora na saúde emocional, permitindo inclusão social 9,24.

Gregório $2013^{9}$ avaliaram a influência da equoterapia no controle cervical e de tronco após nove sessões, uma vez por semana, realizadas em uma criança de dois anos, não recebeu outras intervenções fisioterapêuticas. O tratamento incluía meios lúdicos, iniciado com alongamentos. Montarias com apoio foram utilizadas, porém eram retiradas de acordo com o ganho de controle da criança. Esta apresentou melhora da simetria corporal, do controle cervical e de tronco, benefício psicológico, aumento da interação 
interpessoal e de concentração para atividades em linha média.

Entretanto, no estudo realizado por McGee 200924, no qual seis crianças que realizaram tratamento com equoterapia foram avaliadas para verificar os benefícios imediatos na marcha, não foram encontrados resultados significantes. A principal limitação do estudo foi o curto período de tratamento, consistindo em uma única sessão, que provavelmente não foi suficiente para efetuar alterações neurais e gerar aprendizado motor.

Enfim, com base na revisão realizada, dentre os aspectos clínicos que caracterizam a PC tetraparesia espástica, a espasticidade e as alterações musculoesqueléticas são relacionadas à maiores limitações na independência funcional. Foi possível observar que apesar de haver diversos tipos de tratamento fisioterapêutico adotados para essa população, são limitados os estudos para que seja possível comprovar a eficácia dos métodos utilizados.

Embora a crioterapia tenha apresentado bons resultados, eles foram delimitados quanto a sua duração. A equoterapia permitiu a aquisição de marcos motores importantes, quando realizada em longo prazo. Em relação aos efeitos em longo prazo, o uso de vestes elásticas, que é realizado de maneira intensiva, também apresentou bons desfechos. A utilização de piscina terapêutica demonstrou ganhos na função motora grossa, que quando combinada ao solo, possui maiores resultados. O conceito Bobath, o mais 
descrito na literatura, não apresentou divergências, sendo considerado um método efetivo e confiável.

\section{CONCLUSÃO}

A revisão realizada aponta para a importância do diagnóstico precoce em pacientes com PC tetraparesia espástica, a fim de iniciar o tratamento fisioterapêutico o mais breve possível, diminuindo e prevenindo complicações devido ao acometimento neurológico. Este que, quando realizado em crianças, deve incluir atividades lúdicas para aceitação e contribuição na terapia.

Embora sejam diversos os tipos de abordagem adotadas, a fisioterapia convencional é associada a outros métodos e protocolos. Mostrando-se, dessa forma, efetiva para a melhora do quadro clínico do paciente quanto ao aumento da independência funcional.

As diversas estratégias de tratamento mostraram melhoras na aquisição motora e funcionalidade, detectadas por diferentes instrumentos de avaliação. Porém, devido ao baixo índice de descrições de abordagens e publicações realizadas, não é possível delimitar qual seria o método mais indicado e efetivo para o tratamento desses pacientes. Em grande parte dos estudos, ou autores reiteram a importância de considerar a individualidade de cada um e de buscar atingir os objetivos estabelecidos de acordo com as avaliações realizadas. 


\section{REFERÊNCIAS}

1.Dias CP, Goulart NBA, Freire B, Becker J, Vaz MA. Paralisia cerebral em Pediatria. Rev Ped Mod 2015;51:224-9.

https://www.researchgate.net/publication/281638217 Paralisia cerebral e $\mathrm{m}$ Pediatria Cerebral palsy in Pediatrics

2. Cortés $A$, Wachhotz $D$. Intervención temprana en niños com alto riesgo de desarrollar parálisis cerebral; una revisión sistemática. Rev Chil Terap Ocupac 2016;16:63-76. https://doi.org/10.5354/0719-5346.2016.44752

3.Chagas PSC, Defilipo EC, Lemos RA, Mancini MC, Frônio JS, Carvalho RM. Classificação da função motora e do desempenho funcional de crianças com paralisia cerebral. Rev Bras Fisioter 2008;12:409-16.

https://doi.org/10.1590/ S1413-35552008000500011

4. Oliveira BL, Dantas ACLM, Paiva JC, Leite LP, Ferreira PHL, Abreu TMA. Recursos fisioterapêuticos na paralisia cerebral pediátrica. Rev Cient Esc Saúde $2013 ; 2: 25-37$.

https://repositorio.unp.br/index.php/catussaba/article/view/296

5.Santos TS, Santos MCC, Santos EL. Efeito agudo da crioterapia na espasticidade de crianças com encefalopatia crônica não progressiva da infância. Rev UniAndr 2019;20:9-17.

https://doi.org/10.18024/1519-5694/revuniandrade.v20n1p9-17

6.Azevedo SMS, Santos F. O efeito do método Therasuit na função motora de uma criança com paralisia cerebral: estudo de caso (Trabalho de Conclusão de Curso). Porto: Universidade Fernando Pessoa, 2014. http://hdl.handle.net/10284/4336

7. Oliveira LL, Nery LC, Gonçalves RV. Efetividade do método pediasuit na função motora grossa de uma criança com paralisia cerebral. Rev Interdiscipl Cienc Med 2018;1:15-21.

http://revista.fcmmg.br/ojs/index.php/ricm/article/download/68/30

8. Espindula AP, Junior DEB, Ribeiro MF, Lage JB, Mello EC, Raizel JBE, et al. Avaliação da flexibilidade de crianças com paralisia cerebral após intervenção fisioterapêutica. Rev Cons Saude 2018;17:41-7.

https://doi.org/10.5585/ConsSaude.v17n1.7576

9.Gregório A, Krueger E. Influência da equoterapia no controle cervical e de tronco em uma criança com paralisia cerebral. Rev Uniandr 2013;14:65-75. https://www.researchgate.net/publication/277613935 Influencia da Equot erapia no Controle Cervical e de Tronco em Uma Crianca com Paralisi a Cerebral/fulltext/56410de608ae24cd3e40e685/Influencia-da-

Equoterapia-no-Controle-Cervical-e-de-Tronco-em-Uma-Crianca-com-

Paralisia-Cerebral.pdf

10.Pastrello FHH, Garcão DC, Pereira K. Método watsu como recurso complementar no tratamento fisioterapêutico de uma criança com paralisia cerebral tetraparetica espástica: estudo de caso. Fisioter Mov 2009;22:95102. https://periodicos.pucpr.br/index.php/fisio/article/view/19369/18717

11.Arshad N, Imran M, Munir Z, Akram S, Hameed AA. Spastic cerebral palsy; Effects of Bobath motor developmental techniques in spastic cerebral palsy; a case series. Profess Med J 2018;25:1546-51.

https://doi.org/10.29309/TPMJ/18.4614

12. Morell OJA, Ortega FZ, Obispo BP, Porcel RM. Asociación entre respuesta de equilibración del erector de columna y alteraciones de cadera en la parálisis cerebral. Investig Discapacid 2014;3:153-61.

https://www.medigraphic.com/pdfs/invdis/ir-2014/ir144a.pdf

13. Catena F, Moraes ERM, Lemos AVKC, Yamane PC, Blumetti FC, Dobashi $\mathrm{ET}$, et al. Estudo clínico do quadril não tratado na tetrapareisa espástica. Rev 
Bras Ortop 2011;46(Supp 4):21-6. https://doi.org/10.1590/S010236162011001000005

14.Tremblay ES, Shevell M, Dagenais L. Determinants of ambulation in children with spastic quadriplegic cerebral palsy: a population-based study. J Child Neurol 2009;25:669-73. https://doi.org/10.1177/0883073809342590 15.Firmino RCB, Lima AKP, Almeida CMRS, Uchôa SMM. Influência do Conceito Bobath na função muscular da paralisia cerebral quadriplégica espástica. Rev Neurocienc 2015;23:595-02.

https://doi.org/10.34024/rnc.2015.v23.7992

16. Castano PRL, Gelves MVC, Urazan DP. Abordaje de un caso de parálisis cerebral espástica nível $V$ mediante el concepto Bobath. Rev Sci Dir 2019;41:242-6. https://doi.org/10.1016/j.ft.2019.03.006

17.Ávila ASC, Rocha CAQC. Atuação fisioterapêutica em paciente com PC com tetraparesia espástica assimétrica: um estudo de caso. Rev Cien Faminas 2014;10:21-7.

http://periodicos.faminas.edu.br/index.php/RCFaminas/article/view/341/31 $\underline{6}$

18.Gomes CO, Golin MO. Tratamento Fisioterapêutico Na Paralisia Cerebral Tetraparesia Espástica, Segundo Conceito Bobath. Rev Neurocienc 2013;21:278-85. https://doi.org/10.34024/rnc.2013.v21.8293

19.Porras VA, Pedersini P, Berjano P, Villafañe JH. The efficacy of physical therapy on the improvement of the motor componentes of visual attention in children with cerebral palsy: a case series study. J Exerc Rehabil 2019;15:103-8. https://doi.org/10.12965/jer.1836568.284

20.Ferreira AAS, Fernandes DSSL. Influência da crioterapia e do calor ultrassônico na paralisia cerebral: relato de caso. Rev Neurocienc 2012;20:552-9. https://doi.org/10.4181/RNC.2012.20.710.8p

21. Oliveira L, Santos MCC, Melo TR. Efeito da terapia neuromotora intensiva no controle de tronco de crianças com quadriparesia. Rev UniAndr 2018; 19:77-83. https://doi.org/10.5935/15195694.20180010/revuniandrade.v19n2p77-83

22.Silva EF, Azevedo E, Souza RJ, Favero FM, Frutuoso JRC, Voos MC. Reflexões sobre a importância dos exercícios terapêuticos para 0 desenvolvimento de uma criança com tetraparesia espástica, relato de caso. Rev Ibirapuera 2014;7:21-30. http://www.revistaunib.com.br/vol7/05.pdf 23. Navarro FM, Machado BBX, Neri AD, Ornellas E, Mazetto AA. A importância da hidrocinesioterapia na paralisia cerebral: relato de caso. Rev Neurocienc 2019;17:371-5. https://doi.org/10.34024/rnc.2009.v17.8532

24.McGee MC, Reese NB. Immediate effects of a hippotherapy session on gait parameters in children with spastic cerebral palsy. Pediatr Phys Ther 2009;21:212-8. https://doi.org/10.1097/PEP.0b013e3181a39532 